\title{
Regarding assessing G-Probe function
}

Eye (2003) 17, 123-124. doi:10.1038/

sj.eye. 6700286

In recent years, ciliary trans-scleral cyclophotocoagulation has been adopted as a helpful intervention for challenging cases of recalcitrant glaucoma. The procedure is usually performed with contact fibreoptic delivery of either infrared $(1064 \mathrm{~nm})$ neodymium/YAG or nearinfrared (about $810 \mathrm{~nm}$ ) diode laser light energy, with the latter being a widely available method. A California company (IRIDEX Corporation, IRIS Medical Instruments, Mountain View, CA, USA) developed for use with their diode laser eye treatment console a hemisphere-tipped $400 \mu \mathrm{m}$ diameter fibreoptic delivery device specifically for trans-scleral cyclophotocoagulation - the G-Probe. While treatment with the G-Probe has become popular, the stipulation by the US Food \& Drug Administration that it be packaged and sold as a single-use device ${ }^{1}$ imposes costly impediments to usage. Some physicians reuse the probes.

Several questions arise when considering the reuse of G-Probes. The first is whether a probe after use for a glaucoma treatment has reduced output. $^{2}$ Is the fibre changed by delivering light to the surface of the eye? The second is whether cleansing or sterilizing a probe after use for a treatment affects its function during a subsequent procedure. Another issue is sterility of the probe after use and cleansing.

In a thoughtful study reported in this issue of the journal, Hossain et $a l^{3}$ assess practice patterns in the United Kingdom regarding the reuse of G-Probes, and they present an inventive method to measure probe output. They report a widespread reuse of G-Probes, so it makes sense that they also identify a clinically feasible way to assess probe function after previous use. They detail, and test, a method to measure diode laser burns on patches printed on paper in stepwise depths of grey; they assess the performance of five new probes; and they

DE Gaasterland

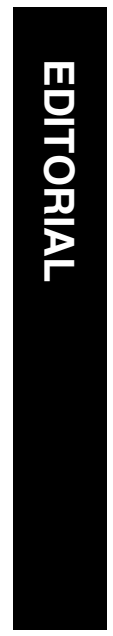

compare a single probe after use for six clinical treatments with a new probe. The output of the used probe is reduced compared with the new probe. They carefully cleanse probes with alcohol between use, which is probably a widespread practice, but their report does not address the issue of sterility.

While the method proposed in the report provides clinical guidance, their study of probe function is not quantitative, and their method of probe assessment suffers weaknesses due to physical optics considerations and printer output properties. The hemisphere tip of the fibreoptic of the probe has a radius of curvature of $200 \mu \mathrm{m}$. This creates a lens with a focal length of $0.4 \mathrm{~mm}$ (lens power $2500 \mathrm{D}$ ) when light exits the fibre into air. Their probe holder places the tip of the fibre $2 \mathrm{~mm}$ from the target paper, so the cross-section of the beam at the paper has a calculated diameter of $1.6 \mathrm{~mm}$ and an area of $2.01 \mathrm{~mm}^{2}$. A variation of only $0.2 \mathrm{~mm}$ in fibre location would alter the area of the spot size by about 25\% (ranging from diameter $1.4 \mathrm{~mm}$ and area $1.54 \mathrm{~mm}^{2}$ for the fibre too close by $0.2 \mathrm{~mm}$ up to diameter $1.8 \mathrm{~mm}$ and area $2.54 \mathrm{~mm}^{2}$ for the fibre too distant by $0.2 \mathrm{~mm}$ ). This may explain why the new probe used for comparison with the used probe in the third part of the authors' report differed in spot diameter from the five probes in the second part of the report.

There is loss of light energy output at the tip from total internal reflection upon testing a fibreoptic in air. This loss is reduced by the index of refraction matching, such as occurs when the probe tip is linked to ocular tissue by intervening conjunctival surface lubricating fluid, as recommended by the manufacturer. ${ }^{1}$

Finally, there is potential variation in the printed grey-scale density when different printers receive the same digital instructions or the same printer at different times. This can arise from differences in ink composition or paper composition. For example, my printer at 'scale 8 ' probably does not replicate yours.
University Ophthalmic

Consultants of

Washington DC

Massachusetts Avenue NW

Washington DC, USA

Correspondence:

DE Gaasterland

University Ophthalmic

Consultants of

Washington DC

4910 Massachusetts Avenue

NW, Suite 210,

Washington DC 20016, USA

Tel: +1-202 6865127

Fax: +1-202 6866668

E-mail: degaasterland@

att.net 
The authors of this report provide useful, new information about practice patterns and a method we can use to reassure ourselves that our G-Probes are functioning. Their measurements of output of one used probe suggest a somewhat reduced transmission, as has previously been reported in a study using a power meter with laser light transmission through air. ${ }^{2}$ While it is not appropriate to regard their testing method as quantitative, it is nonetheless potentially clinically useful and reassuring.

\section{References}

1 IRIS G-Probe ${ }^{\mathrm{TM}}$. IRIS Oculight Diode Laser System Operator Manual, Chapter 12. IRIS Medical Instruments: Mountain View, CA, 1993, pp 12-1-12-12.

2 Tham CCY, Lai JSM, Fung PCW, Chua JKH, Poon ASY, Lam DSC. Physical effect of reuse and repeated ethylene oxide sterilization on transscleral cyclophotocoagulation laser G-Probes. J Glaucoma 2002; 11: 21-25.

3 Hossain P, Ghosh G, Vernon SA. Assessing the 'cyclodiode G-Probe' using a grey scale test-reproducibility and differences between probes. Eye 2003; 17: 165-174. 